\title{
Empowering patients of a mental rehabilitation center in a low-resource context: a Moroccan experience as a case study
}

This article was published in the following Dove Press journal:

Psychology Research and Behavior Management

10 April 2017

Number of times this article has been viewed

\section{Hicham Khabbache' \\ Abdelhak Jebbar ${ }^{2, *}$ \\ Nadia Rania 3 * \\ Marie-Chantal Doucet ${ }^{4}$ \\ Ali Assad Watfa ${ }^{5}$ \\ Joël Candau 6 \\ Mariano Martini ${ }^{7}$ \\ Anna Siri ${ }^{8, *}$ \\ Francesco Brigo 9,10,* \\ Nicola Luigi Bragazzi 1,2,4-8,11,* \\ 'Faculty of Literature and Humanistic Studies, Sais, Sidi Mohamed Ben Abdellah University, Fez, ${ }^{2}$ Faculty of Art and \\ Humanities, Sultan Moulay Slimane University, Beni-Mellal, Morocco; ${ }^{3}$ School of Social Sciences, Department of Education Sciences, University of Genoa, Genova, Italy; ${ }^{4}$ Faculty of Human Sciences, School of Social Work, University of Québec-Montréal, Montreal, QC, Canada; ${ }^{5}$ Faculty of Education, Kuwait University, Kuwait City, Kuwait; ${ }^{6}$ Laboratory of Anthropology and Cognitive and Social Psychology, University of Nice Sophia Antipolis, Nice, France; ${ }^{7}$ Department of Health Sciences (DISSAL), Section of Bioethics, University of Genoa, ${ }^{8}$ UNESCO \\ Chair "Health Anthropology, Biosphere and Healing Systems”, Genova, 'Department of Neurology, Franz Tappeiner Hospital, Merano, ${ }^{10}$ Department of Neurological, Biomedical, and Movement Sciences, University of Verona,Verona, "School of Public Health, Department of Health Sciences (DISSAL), University of Genoa, Genova, Italy \\ *These authors contributed equally to this work}

Correspondence: Nicola Luigi Bragazzi School of Public Health, Department of Health Sciences (DISSAL), University of Genoa, Via

Antonio Pastore I, Genova 16132, Italy

Tel +390I 03537664

Fax +390I 03537669

Email robertobragazzi@gmail.com

Hicham Khabbache

Tel +212675059355

Fax +2125356I 8253

Email hichamcogn@gmail.com
Abstract: Mental, neurological and substance use (MNS) disorders represent a major source of disability and premature mortality worldwide. However, in developing countries patients with MNS disorders are often poorly managed and treated, particularly in marginalized, impoverished areas where the mental health gap and the treatment gap can reach $90 \%$. Efforts should be made in promoting help by making mental health care more accessible. In this article, we address the challenges that psychological and psychiatric services have to face in a low-resource context, taking our experience at a Moroccan rehabilitation center as a case study. A sample of 60 patients were interviewed using a semi-structured questionnaire during the period of 2014-2015. The questionnaire investigated the reactions and feelings of the patients to the rehabilitation program, and their perceived psychological status and mental improvement, if any. Interviews were then transcribed and processed using ATLAS.ti V.7.0 qualitative analysis software. Frequencies and co-occurrence analyses were carried out. Despite approximately 30 million inhabitants within the working age group, Morocco suffers from a shortage of specialized health workers. Our ethnographic observations show that psychiatric treatment can be ensured, notwithstanding these hurdles, if a public health perspective is assumed. In resource-limited settings, working in the field of mental health means putting oneself on the line, exposing oneself to new experiences, and reorganizing one's own skills and expertise. In the present article, we have used our clinical experience at a rehabilitation center in Fes as a case study and we have shown how to use peer therapy to overcome the drawbacks that we are encountered daily in a setting of limited resources.

Keywords: peer therapy, low-resource setting, patient empowerment, qualitative analysis

\section{Introduction}

It would be difficult to imagine what human life would be like without stories ${ }^{1}$

Mental, neurological and substance use (MNS) disorders represent a major source of disability and premature mortality worldwide, imposing a tremendous burden both in terms of epidemiology and costs. ${ }^{2,3}$ However, in developing countries patients with MNS disorders are often poorly managed and treated, particularly in marginalized, impoverished areas, ${ }^{4}$ where the mental health gap and the treatment gap can reach $90 \% .^{5}$

Efforts should be made in promoting help by making mental health care more accessible. ${ }^{6}$ Psychiatric cures can be ensured, notwithstanding these hurdles, if a public health perspective is assumed. ${ }^{7}$ In resource-limited settings, working in the field of mental health calls for putting oneself on the line, exposing oneself to new experiences, and reorganizing one's own skills and expertise. However, this means big efforts, a lot of 
commitment, and resilience to negative outcomes and stress. Psychologists/psychiatrists become artisans that rediscover the centrality of the patient and the quotidian dimension of their work. Human capital is indeed highly important and precious in low-and-middle-income countries (LMICs). ${ }^{8}$

This aspect is crucial but overlooked in the extant literature, ${ }^{9-15}$ which instead focuses on technical issues such as task shifting, scaling-up approaches, emphasizing the socio-economic dimension, but poorly investigating the psychological and cognitive challenges of operating in resourceconstrained environments from a qualitative point of view.

In this article, we address the challenges that psychological and psychiatric services have to face in a low-resource context, taking our experience at a Moroccan mental rehabilitation center as a case study.

\section{Patients and methods}

\section{Sample and sampling procedure}

After volunteering to take part in this study, a convenience sample of 60 patients (representing one half to one third of the patients housed in the center) were interviewed using a semistructured questionnaire during the period of 2014-2015. The questionnaire investigated the reaction and feelings of the patients to the rehabilitation program, and their perceived psychological status and mental improvement, if any.

The participants were aged between 18-33 years, 12 females and 48 males, and were affected by psychotic disorders, while the clinical staff of the association comprised of three nurses, one secretary, and five social workers and assistants.

All participants were informed about the objectives of the study and gave their written informed consent to participate in the study. Ethical clearance was obtained by the Institutional Ethics Review Board of the Sidi Mohamed Ben Abdellah University, Fez, Morocco.

\section{Implementation of the task-shifting program}

We implemented and qualitatively evaluated a psychiatric "task-shifting" program and a self-empowerment-based peer therapy for a rural, underserved community. The program was added to a preexisting medical program in the University Hospital of Psychiatry in Fez and utilized community workers belonging to an association to improve health care delivery.

Our reorganization of psychiatric program was prompted by administrative, social, economic, and political issues, with many volunteering psychiatrists leaving the association.

Our program was articulated in different steps and subplans. We worked both on the personnel and on the patients. To reduce the burnout and stress due to the high work load, we taught the clinical staff a self-empowerment-based approach, comprising different metacognitive activities requiring a certain degree of awareness through five processes, namely "self-description" (how do the participants describe and share their experiences, including the problems, with their colleagues?), "self-regulation" (how do the participants strike a balance between their work at the association and their private life?), "self-monitoring" (how do the participants analyze and perceive the evolution and the dynamics within the association?), "self-modification" (how do the participants treat and cope with the problems?), and "selfconcept" (how do the participants elaborate new knowledge upon strategies rationally founded and supported in order to face new unexpected situations?). ${ }^{16}$

The association provided the following therapeutic activities: group therapy, individual therapy based on emotional expression and family interventions with the aim of sensitizing the family on the competences transfer and on the convenient manner to behave with the patient. Furthermore, we provided the patients a diversified array of workshops such as ceramic and decoration workshops, drawing and writing workshop, and music, sport, and computing workshops.

It should be emphasized that within a workshop different activities were provided on the basis of the socio-cultural and alphabetization status of the patient: for example, during the writing workshop, illiterate patients were alphabetized, being taught how to write and read from the very scratch, while literate patients were taught creative writing at a more advanced level. In particular, they were asked and instructed to write about a topic of their choice, not necessarily based on their clinical and personal story. A "humanities paradigm"17-19 was preferred to a "scientific paradigm"20-24 which, as in a randomized controlled trial, makes use of controls and implies highly standardized, structured writing sessions. We privileged, instead, more unstructured, open-ended, and exploratory sessions. Further, we informed the patients that their stories and any written material would have been shared not only with the clinical staff but also with every patient taking part in the therapeutic intervention.

The program was based on the principles of co-creation, integration, scalability, reflexivity, and self-empowerment, as advocated by the WHO agenda that called for comprehensive, coordinated actions and responses. ${ }^{3}$ Further, we worked also on the religiosity and spirituality of the patients.

\section{Qualitative analysis}

We performed a thematic field analysis, one of the most common approaches used in the field of qualitative research. ${ }^{25}$ This method of text analysis implies a recursive and iterative 
process of carefully reading, coding, examining, recording, reviewing, and analyzing meaningful patterns (known as "themes") and their variations associated with our research questions.

Interviews were transcribed and processed using ATLAS. ti V.7.0 qualitative analysis software (ATLAS.ti GmbH, Berlin, Germany). Frequency and co-occurrence analyses were carried out.

\section{Results}

\section{Effects of the program}

The most attended workshop was the writing workshop: patients felt themselves personally involved. Writing was exploited as a therapeutic exercise and an introspective, supportive tool, with patients freely expressing and communicating their own experiences.

When I am writing, I feel that I am really and deeply talking with myself. [Patient 1]

I feel inside, I understand, I develop my consciousness of myself and of the world. [Patient 4]

Writing enabled patients to understand better themselves, helping them to explore their feelings. Therefore, writing was perceived as being extremely meaningful, rewarding, and helpful.

Moreover, writing enabled to create and establish an authentic therapeutic place. We noticed that writing exerted a disinhibiting power, enabling the patient to enter in contact with the clinical staff and his/her mates.

When I read the suffering of the others through their writings

I feel that this suffering is also mine. [Patient 1]

I feel that he is starting to share with me his intra-psychic life, his tastes, his envies, his joys, his suffering, his wishes, and his projects. [Patient 2]

Patients were able to disclose details before unrevealed. Writing helped them to relief ailments and struggles, and to reduce the stigma, regulating and reframing emotions. The experience of feeling in touch with the others was described in terms of a mystic and "magical" experience.

When I am reading and writing I feel the sentiments of the other, I merge, I lose consciousness of myself and of the world. [Patient 3]

Reading the message of the other has a magical effect which appears in the sentiment of my soul infiltrated in the soul of the other. [Patient 5]

I hear his voice in my head. [Patient 6]
Patient 3 reported an experience of ego transcending, whereas patient 5 described an experience of complete absorption (infiltration).

We observed a parallelism between the achievement in reading and writing and the ability of self-describing as well as a positive effect on mental health and psychological functioning.

Patients became more self-aware and were able to learn new coping strategies, get rid of their own naïve theories, false constructs, and misrepresentations.

Patients began to develop a sense of "narrative competence", which can be defined, according to Stephen Dobson, as the ability "to create multi-directional, multi-punctual and multi-accented narratives". ${ }^{26,27}$ More in details, they begin to use two complementary psycho-cognitive strategies, comparing themselves versus similar or different clinical cases. Reading and writing increased the sense of empathy and improved patient communication with the peers and with the clinical staff. It also reinforced identification with the others in order to better know one-self. Feeling similar to the others and describing his/her own mental states triggered a process of inter-projection. Writing had a "relational" role, that is to say a "bridging" and "connecting" function with the exterior world and with the peers, as well as a "mitigating" effect.

I am not the only to suffer in this world. [Patient 7]

AlhamdoLillah (thanks to God, in Arabic), I am not suffer-

ing as him. I always thank God for relieving my sense of anguish. [Patient 8]

Further, reading and writing gave patients the willingness to express their sufferings, and open accounts in social media using fictitious names to convey their feelings. Interestingly, we found also that several patients tried to acquire a better understanding of their mental troubles by consulting books, journals, and Internet websites dedicated to psychopathology.

Writing helped patients to find a voice, to find their voice, and to develop a coherent, well-organized, meaningful narration resulting in "therapeutic emplotment" ${ }^{23}$ and "clinical meaning". ${ }^{24}$ Besides triggering these cognitive mechanisms, writing also exerted emotive effects and, at least in some patients, helped to reach valued, fulfilling moments, enabling them to express all their potential.

\section{Discussion}

The association helped patients in significantly improving their mental status and psychological well-being. Patients were able to develop a higher sense of insight and 
introspection, mobilizing inner energies and efforts, and reflecting upon their own cognitive and affective schemata.

Notwithstanding many hurdles, taking care of patients was possible after properly reorganizing psychiatric and psycho-social services.

Despite its large and young population made up of $\sim 30$ million inhabitants, Morocco has $<350$ psychiatrists, 60 clinical psychologists, approximately 400 nurses specializing in psychiatry, and a number of social workers. According to the World Health Organization (WHO), in Morocco there is an average of about nine health workers in the field of mental health per 100,000 persons. ${ }^{28}$ This shortage of specialized health workers is dramatically in contrast with the epidemiological and societal burden of MNS disorders (which have an overall prevalence of $40.1 \%-48.9 \%$ in Morocco, with depression and anxiety affecting an estimated $26.5 \%$ and $25.5 \%-37 \%$ of the general population, respectively). ${ }^{28-30}$

Morocco is a transitional society from economic and social points of view, and as such, is experiencing particular challenges, concerning basic education and quality primary health care, elimination of illiteracy, reduction of poverty, social inequality, and unemployment, among others. ${ }^{28,31}$

Our qualitative study demonstrates that self-help and self-empowerment ${ }^{32}$ can play, at least partially, a role in developing countries. In particular, our focus was specifically on teaching cognitive and meta-cognitive skills. Patients learned how to acquire self-scaffolding abilities ${ }^{33}$ and become functionally independent, through identifying and analyzing problems, using relevant self-assistance strategies and assessing the strategies used, and predicting/evaluating outcomes. Becoming more aware of themselves, they could interact more easily with their peers and strengthen/acquire new knowledge (constructive, collaborative learning).

The cognitive process engaged by the patients comprises of five steps: self-regulation or self-modification: the patient reorganizes his own feelings and affective/cognitive states; self-monitoring: the patient begins to understand the moments of particular frailty and relapse; interactive mind-reading: the patient understands the mental troubles of his peers; self-representation: the patient becomes aware of his mental disorder; self-concept: the patient begins to experiment new forms of cure and therapy, introducing some micro-innovations and personal variants.

The results of the writing laboratory seem to support the clinical effectiveness of this intervention. Our findings are in line with what was observed by Pennebaker, who claimed that writing therapy worked helping to develop a coherent narrative of oneself over time, fostering the use of cognitive processing-based approaches and strategies and helping to acquire new cognitive and meta-cognitive skills and abilities, stimulating and promoting reflective thinking. ${ }^{19,20}$ Furthermore, we found that in some patients the writing/reading experience was perceived as a peak experience. Maslow ${ }^{34}$ and Laski, ${ }^{35}$ studying the psychology of creativity, made a parallelism between creative experiences/situations and mystical experiences, linking them to the processes of self-discovery and self-actualization. To the best of our knowledge, there is a dearth of information concerning writing- and/or reading-induced/triggered peak experiences, ${ }^{36}$ and this deserves further examination and study.

Moreover, it should be noted that most patients exploited the new information and communication technologies. Online therapy can be a precious resource in LMICs as it is cost-effective, and can be accessed from various places, such as Internet cafés and hot-spots, as well as from mobile devices and smart-phones. ${ }^{2}$

Our study has a number of strengths and limitations that should be properly acknowledged. To the best of our knowledge, this article is one of the few studies available in the literature which addresses the challenges that psychological and psychiatric services have to face in a low-resource context, showing that peer therapy and online therapy, being cost-effective, can be a precious resource. Few studies have explored the outcome of narrative/creative therapy in developing countries. ${ }^{37}$ However, the present study is based on a qualitative analysis and, as such, should be considered as a preliminary report. Our sample was a convenience sample and, therefore, caution should be taken when generalizing our findings. Our intervention was an ad hoc intervention, which, in the future, should be refined, incorporating evidence-based approaches. On the light of these shortcomings, further quantitative studies should be carried out, prospectically measuring, for example, patients' mental status.

\section{Conclusion}

We can say that, according to our ethnographic data, despite the reorganization of psychiatric services due to different, concurring social, political, economic, and logistic issues, we were nevertheless able to provide patients with effective rehabilitation programs. Patients themselves, in their turn, were able to create their own "self-empowerment" and construct their own psychotherapy, being able to put into practice an approach termed as "Selbstgesteuertes Lernen" (self-regulated learning) by the German pedagogists. ${ }^{38,39}$ 
The great shortage, and inequitable distribution, of psychiatrists in LMICs is one of the key reasons for the large treatment gap for people with mental disorders. Psychiatrists need to play a public mental health leadership role in increasing the coverage of mental health care through task shifting of effective interventions to non-specialist health workers. Psychiatrists' new roles should include designing and managing such programs; building clinical capacity, supervision, and quality assurance; providing different referral pathways and research; ${ }^{40,41}$ and responsibilizing the patients (principle of responsibility or of Eigenverantwortung, according to the German pedagogists). ${ }^{38,39}$ It is also fundamental that patients themselves take part in the designing of rehabilitation programs, in such a way that the program is tailored and targeted to patient's need and becomes more effective.

\section{Acknowledgments}

The current study and its writing received generous financial support from the Canadian "Conseil de recherches en sciences humaines" (CRSH) and from the Moroccan "Association du Travail Social et Développement humain" (ATSDH).

\section{Disclosure}

The authors report no conflicts of interest in this work.

\section{References}

1. Niles JD. Homo Narrans: The Poetics and Anthropology of Oral Literature. Philadelphia: University of Pennsylvania Press; 2010.

2. Arjadi R, Nauta MH, Chowdhary N, Bockting CLH. A systematic review of online interventions for mental health in low and middle income countries: a neglected field. Global Ment Health. 2015; 2:e12.

3. World Health Organization. Global burden of mental disorders and the need for a comprehensive, coordinated response from health and social sectors at the country level. Available from: http://apps.who. int/gb/ebwha/pdf_files/EB130/B130_9-en.pdf. Accessed March 2, 2016.

4. Nimgaonkar AU, Menon SD. A task shifting mental health program for an impoverished rural Indian community. Asian J Psychiatr. 2015;16:41-47.

5. Chisholm D, Flisher AJ, Lund C, et al; Lancet Global Mental Health Group. Scale up services for mental disorders: a call for action. Lancet. 2007;370(9594):1241-1252.

6. Huessy HR. Mental Health with Limited Resources. New York, NY: Grune \& Stratton; 1966.

7. World Health Organization (WHO) and Ministry of Health, Rabat, Morocco. WHO - Assessment Instrument for Mental Health Systems (WHO-AIMS). Report on mental health system in Morocco; 2006. Available from: http://www.who.int/mental_health/evidence/morocco who_aims_report.pdf. Accessed March 2, 2016.

8. Patel V. The future of psychiatry in low- and middle-income countries. Psychol Med. 2009;39(11):1759-1762.
9. Ventevogel P. Integration of mental health into primary healthcare in low-income countries: avoiding medicalization. Int Rev Psychiatry. 2014;26(6):669-679.

10. Alem A, Pain C, Araya M, Hodges BD. Co-creating a psychiatric resident program with Ethiopians, for Ethiopians, in Ethiopia: the Toronto Addis Ababa Psychiatry Project (TAAPP). Acad Psychiatry. 2010;34(6):424-432.

11. Dharmono S. Mental Health in the Context of Conflict and Violence in Indonesia. Melbourne, Australia: Centre for International Mental Health, University of Melbourne; 2005.

12. Griffith JL, Myers N, Compton MT. How can community religious groups aid recovery for individuals with psychotic illnesses? Community Ment Health J. 2015;52(7):775-780.

13. Thirthalli J. Reflections on task-shifting as a method of reducing treatment gap in low-middle income countries. Asian J Psychiatr. 2015;16:1-2.

14. Fekadu A, Hanlon C, Medhin G, et al. Development of a scalable mental healthcare plan for a rural district in Ethiopia. Br J Psychiatry. 2016; 208(Suppl 56):S4-S12.

15. Jordans MJ, Luitel NP, Pokhrel P, Patel V. Development and pilot testing of a mental healthcare plan in Nepal. Br J Psychiatry. 2016;208(Suppl 56):S21-S8

16. Khabbache H, Berdai A. Social Work and Human Development and Empowerment of Skills. 2012, Fes: International Institute of Anthropology and Sociology and Human development Press; 2012.

17. Bolton G. The Therapeutic Potential of Creative Writing. London, UK: Jessica Kingsley; 1999.

18. Greenhalgh T. Writing as therapy. BMJ. 1999;319:270-271.

19. Pennebaker JW. Opening Up: The Healing Power of Expressing Emotions. New York, NY: Guilford Press; 1997.

20. Pennebaker JW. Writing about emotional experiences as a therapeutic process. Psychol Sci. 1997;8(3):162-166.

21. Smyth JM, Pennebaker JW. Sharing one's story: translating emotional experiences into words as a coping tool. In: Snyder CR, editor. Coping: The Psychology of What Works. New York, NY: Oxford University Press; 1999:70-89.

22. Baikie KA, Wilhelm K. Emotional and physical health benefits of expressive writing. Adv Psychiatr Treat. 2005;11(5):338-346.

23. Mattingly C. The concept of therapeutic 'emplotment'. Soc Sci Med. 1994;38(6):811-822.

24. Peterkin AD, Prettyman AA. Finding a voice: revisiting the history of therapeutic writing. Med Humanit. 2009;35(2):80-88.

25. Friese S. Qualitative Data Analysis with ATLAS.ti. 2011.

26. Bolton G. Narrative writing: reflective enquiry into professional practice. Educational Action Research. 2006;14(2):203-218.

27. Dobson S. Narrative competence and the enhancement of literacy. some theoretical reflections. Seminar.net - Int J Media Technol Lifelong Learn. 2005;1(2):1-14

28. Moussaoui D. Psychiatry and mental health in Morocco. Bull Acad Natl Med. 2007;191(4-5):781-782. French.

29. Kadri N, Agoub M, El Gnaoui S, Berrada S, Moussaoui D. Prevalence of anxiety disorders: a population-based epidemiological study in metropolitan area of Casablanca, Morocco. Ann Gen Psychiatry. 2007;6:6.

30. Kadri N, Agoub M, Assouab F, et al. Moroccan national study on prevalence of mental disorders: a community-based epidemiological study. Acta Psychiatr Scand. 2010;121(1):71-74.

31. Kakuma R, Minas H, van Ginneken N, et al. Human resources for mental health care: current situation and strategies for action. Lancet. 2011;378(9803):1654-1663.

32. Nayar K, Kyobutungi C, Razum O. Self-help: what future role in health care for low and middle-income countries? Int J Equity Health. 2004; $3(1): 1$.

33. Holton D, Clarke D. Scaffolding and metacognition. Int J Math Educ Sci Technol. 2006;37(2);127-143.

34. Maslow AH. Lessons from peak experience. J Humanistic Psychol. 1962;2:9-18. 
35. Laski M. Ecstasy: a Study of Some Secular and Religious Experiences. London, UK: The Cressent Press; 1961.

36. Fatemi J. An exploratory study of peak experience and other positive human experiences and writing. Dissertation, University of Toledo, 2004.

37. Vaandrager $\mathrm{C}$, Pieterse $\mathrm{H}$. The pen and the couch: possibilities for creative writing and narrative therapy in South Africa. The Social Work Practitioner Researcher. 2008;20(3):391-405.

38. Bannach M. Selbstbestimmtes Lernen. Frei Arbeiten an selbstgewählten Themen. Schneider-Verlag, Baltmannsweiler;2002, ISBN 3-89676-525-6.
39. Spörer N. Strategie und Lernerfolg. Validierung eines Interviews zum selbstgesteuerten Lernen [Strategy and learning success: Validation of an interview for self-directed learning]. Dissertation in der Humanwissenschaftlichen Fakultät der Universität Potsdam; 2003. Available from: https://publishup.uni-potsdam.de/opus4-ubp/frontdoor/index/index/ docId/13. Accessed February 1, 2017.

40. Okasha A, Karam E. Mental health services and research in the Arab world. Acta Psychiatr Scand. 1998;98(5):406-413.

41. Lund C, Tomlinson M, Patel V. Integration of mental health into primary care in low- and middle-income countries: the PRIME mental healthcare plans. Br J Psychiatry. 2016;208(Suppl 56):S1-S3.

\section{Publish your work in this journal}

Psychology Research and Behavior Management is an international, peerreviewed, open access journal focusing on the science of psychology and its application in behavior management to develop improved outcomes in the clinical, educational, sports and business arenas. Specific topics covered in the journal include: Neuroscience, memory and decision making; Behavior modification and management; Clinical applications; Business and sports performance management; Social and developmental studies; Animal studies. The manuscript management system is completely online and includes a very quick and fair peer-review system, which is all easy to use. Visit http://www dovepress.com/testimonials.php to read real quotes from published authors. 